\title{
Enhanced habituation produced by posttrial peripheral injection of substance $P$
}

\author{
MARIA S. AGUIAR and CARLOS TOMAZ \\ University of São Paulo at Ribeirão Preto, Ribeirão Preto, Brazil
}

(José Aparecido da Silva, Sponsor)

\begin{abstract}
Two experiments were undertaken to investigate the effects of the neuropeptide Substance $P$ (SP) on habituation performance in rats. Habituation was measured in an open field by recording the number of rearings during $2 \mathrm{~min}$ of free exploration. Training and test sessions were identical and $24 \mathrm{~h}$ apart. The animals were injected i.p. immediately after the training trial in doses of $0.5,1,5,50,100$, or $250 \mu \mathrm{g} / \mathrm{kg}$ SP; control animals were injected with diluent vehicle or were not injected at all. The $50 \mu \mathrm{g} / \mathrm{kg}$ SP treatment group showed significantly better performance than the other groups. In the second experiment, $50 \mu \mathrm{g} / \mathrm{kg}$ SP or vehicle was injected either immediately or $5 \mathrm{~h}$ after training. Only the group in which SP was injected immediately after the training trial showed significantly better performance when tested $24 \mathrm{~h}$ later. These results suggest that SP does not exert its effect by a long-lasting proactive action on performance during the testing trial.
\end{abstract}

Recent evidence points to a functional mnemonic role for the neuropeptide Substance P (SP). It has been shown that in certain regions of the brain, microinjection of SP mimics the effects of posttrial electrical stimulation on learning and memory. For example, posttrial injection of SP into the substantia nigra (Huston \& Stäubli, 1978) and amygdala (Huston \& Stäubli, 1979) disrupted performance of avoidance tasks, whereas injection of SP into the lateral hypothalamus/medial forebrain bundle (Stäubli \& Huston, 1979), the septum (Stäubli \& Huston, 1980), and the nucleus basalis magnocellularis (Kafetzopoulos, Holzhäuer, \& Huston, 1986) facilitated such performance.

Systemically applied, SP also seems to influence the performance of rats and mice on learning tasks. Intraperitoneal (i.p.) administration of SP in rats before training did not influence the learning of an active avoidance task (Hecht, Oehme, Poppei, \& Hecht, 1979), whereas SP administered i.p. immediately after training facilitated the retention of a shock-motivated brightness discrimination (Wetzel \& Matthies, 1982). We have been able to show that posttrial i.p. administration of SP improves retentiontest performance of single-trial inhibitory-avoidance tasks in a dose-dependent way (Tomaz, Aguiar, \& Nogueira, in press; Tomaz \& Huston, 1986). Posttrial subcutaneous administration of SP enhanced the retention-test performance of avoidance conditioning and reversed the amnestic effects of cycloheximide and electroconvulsive

This research was supported by grants from Fundação de Amparo à Pesquisa do Estado de São Paulo and Conselho Nacional de Desenvolvimento Científico e Tecnológico, Brazil, to C. Tomaz. M. S. Aguiar was supported by fellowship from the Coordenação de Aperfeiçoamento de Pessoal de Nível Superior. We thank J. L. Castreghini for his skillful technical assistance. Correspondence may be addressed to C. Tomaz, Laboratory of Psychobiology, FFCLRP-USP, Av. Bandeirantes 3900, 14049 Ribeirão Preto, São Paulo, Brazil. shock in mice (Schlesinger, Lipsitz, Peck, \& Pelleymounter, 1983; Schlesinger, Lipsitz, Peck, Pelleymounter, Stewart, \& Chase, 1983).

As can be observed, most of the learning tasks studied are aversively motivated. Since SP appears to be involved in the transmission of pain (Henry, 1980), it is difficult to be sure that performance is not indirectly influenced by changes in pain mechanisms. Therefore, in the present study, we examined the effects of peripheral SP administration on habituation, since this form of learning does not involve either positive or negative reinforcers.

\section{METHOD}

\section{Subjects and Apparatus}

The experiments were performed on 120 male Wistar rats weighing between 180 and $200 \mathrm{~g}$. They were housed individually, under a 12:12 h light:dark cycle with lights on at 7:00 a.m., at an ambient temperature of $21^{\circ}-24^{\circ} \mathrm{C}$, with food and water available ad lib.

Behavioral observations were carried out in a circular open field $(60 \mathrm{~cm}$ in diameter and $30 \mathrm{~cm}$ high). An 8-W light bulb hanging from the lid at the midline provided constant illumination.

\section{Drug Regimen}

The SP peptide was dissolved in physiological saline containing $0.01 \mathrm{M}$ acetic acid (pH 4.0), deep frozen and diluted shortly before use. Control animals received this diluent vehicle. SP was injected i.p. at doses ranging from 0.5 to $250 \mu \mathrm{g} / \mathrm{kg}$ in a volume of $0.5 \mathrm{ml} / 100 \mathrm{~g}$ body weight. The same volume was used for control animals that received the diluent vehicle. All vessels and syringes were acid-washed.

It is important to point out that all solutions were blind-coded to avoid bias. The person performing the experiment did not know whether the SP or the vehicle had been injected. The drug code was not broken until the experiments had been completed.

\section{Procedure}

Habituation was measured in the open field by recording the numbers of rearings (standing on the hind feet while performing orienting movements with the head). Two identical sessions were carried out. The first will be called the training session and the second one the test ses- 
sion. In the training session, the rats were taken directly from their home cages to the open field, placed on its center, and left to explore the arena for 2 min during which the incidence of rearing responses was measured. Immediately thereafter, the animals were removed from the open field and injected i.p. with the solution. In the second experiment, additional groups were injected $5 \mathrm{~h}$ after the training session.

Twenty-four hours after this session, the animals were again placed in the center of the open field and the incidence of rearing responses was measured. Training and testing sessions were carried out between 1000 and $1400 \mathrm{~h}$.

\section{Statistical Analysis}

Comparisons of the performance of rearing responses among groups were by way of the Mann-Whitney $U$ test for large samples with approximately normally distributed test statistics (Krauth, 1983). In order to avoid a Type I error, which is known to vary with the number of tests conducted (Sakoda, Cohen, \& Beall, 1954), the "reduced alpha method" (Lunney, 1969) was used to adjust the significance level (5\%, two-tailed) for the number of tests conducted

\section{RESULTS}

In the first experiment, SP was injected immediately after the training session in doses ranging from 0.5 to $250 \mu \mathrm{g} / \mathrm{kg}$; control animals were either injected with diluent vehicle or were not injected at all (handling-control group). The results obtained with the diverse posttraining treatments are shown in Figure 1.

Only the group that received the $50 \mu \mathrm{g} / \mathrm{kg} \mathrm{SP}$ injection showed significantly better habituation performance than the vehicle-control group $(p=.014)$. These results suggest that SP injected immediately after the training session at a dose of $50 \mu \mathrm{g} / \mathrm{kg}$ enhances habituation.

The purpose of the second experiment was to determine whether posttrial injection of SP $5 \mathrm{~h}$ after the training session would also have a facilitatory effect on performance. The results showed that, unlike immediate posttrial injection, the delayed SP treatment did not facilitate retention-test performance. Comparison of the number of rearings in the test session showed no significant difference between the SP-delayed and the vehicle-delayed

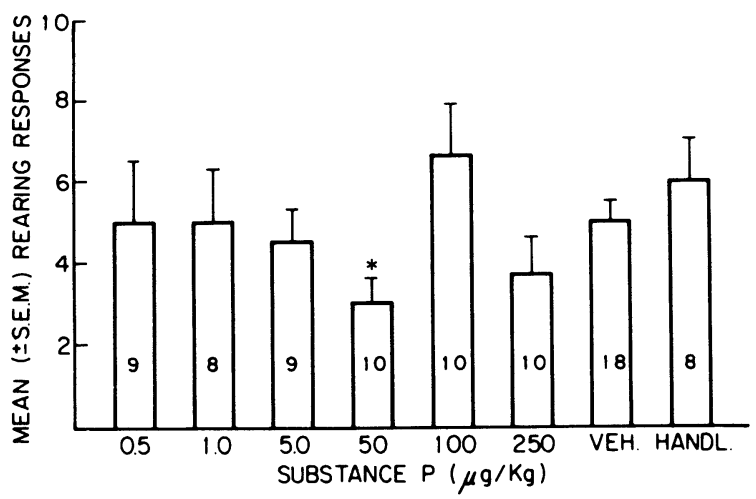

Figure 1. Effects of Substance $P$ administered immediately after training. Habituation was measured in an open field by recording the number of rearings during $2 \mathrm{~min}$ of free exploration. Retention is expressed as the mean $( \pm S E M)$ performance of rearing responses measured $24 \mathrm{~h}$ after training. VEH = vehicle control, HANDL $=$ handling control, * = significant difference. The numbers in the columns indicate the number of animals used in each treatment group.

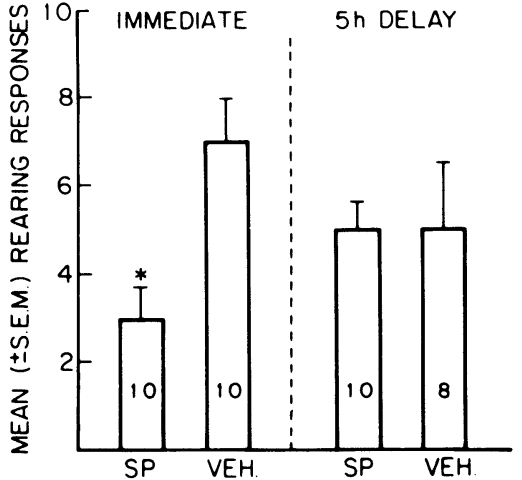

Figure 2. Effects of posttraining administration of Substance $P$ (SP) on habituation measured in an open field by recording the number of rearings during $2 \mathrm{~min}$ of free exploration. Either $50 \mu \mathrm{g} / \mathrm{kg}$ SP or vehicle (VEH) was administered either immediately after training or $5 \mathrm{~h}$ later. Retention is expressed as the mean ( $\pm S E M)$ performance of rearing responses measured $24 \mathrm{~h}$ after training. * = significant difference.

groups $(p=.595)$. However, improved performance was observed for the group treated with SP immediately after training, as in the first experiment. Statistical comparisons revealed significant differences between the SPimmediate and the vehicle-immediate groups $(p=.016)$ as well as between the SP-immediate and the SP-delayed groups $(p=.027)$. Figure 2 summarizes the results of this experiment.

\section{DISCUSSION}

The main result of the present study is that peripheral posttrial administration of SP enhances between-trial habituation in a dose-dependent way. Only $50 \mu \mathrm{g} / \mathrm{kg} \mathrm{SP}$ improved performance of the habituation task; lower and higher doses were ineffective. In addition, the results of the second experiment indicate that the facilitatory effect of SP treatment on performance was not due to a long-lasting proactive influence on performance $24 \mathrm{~h}$ after the injection. These results are in agreement with those in which similar dose-response effects of central and peripheral administration of SP have been reported for the facilitation of performance of various learning tasks (Huston \& Stäubli, 1981; Schlesinger, Lipsitz, Peck, Pelleymounter, Stewart, \& Chase, 1983; Tomaz et al., in press; Tomaz \& Huston, 1986).

Habituation carried over into the test session has been considered a measure of memory (Izquierdo, 1979; Thompson \& Spencer, 1966). Thus, the results obtained in the present study provide further evidence for a role of SP in mnemonic processes.

Regarding the possible site of action of SP, some studies (Banks \& Kastin, 1985; Stern \& Hadzovic, 1973) have shown that this neuropeptide can cross the blood-brain barrier. Thus, it is thought that the effects on learning obtained with peripheral administration of SP might be due in part to a central action of the neuropeptide. This is all the more likely since anatomical localization of SP-containing fibers has been demonstrated in all regions of the brain where learning- and memory-modulating effects of SP were found (Cuello \& Kanazawa, 1978; Ljungdahl, Hökfelt. \& Nilsson, 1978). If these effects are central, it remains to be determined where and in interaction with what neurotransmitters SP is active. It is possible that the effects of SP may be due, for example, to an interaction of SP with dopaminergic neurons in the lateral hypothalamus/medial forebrain bundle, with cholinergic neurons in the nucleus basalis magnocellularis, and/or with endogenous opioids. However, it is also possible that a direct peripheral effect of SP could be responsible for the facilitation of learning observed in various learning tasks. 
In conclusion, the present results show that SP facilitates not only aversive or positively motivated learning tasks, but habituation as well, which is a form of learning that does not involve either positive or negative reinforcers. Thus, our results, taken together with data from the literature, strongly suggest a role for SP in mnemonic processes.

\section{REFERENCES}

Banks, W. A., \& Kastin, A. J. (1985). Peptides and the blood-brain barrier: Lipophilicity as a predictor of permeability. Brain Research Bulletin, 15, 287-292.

Cuello, A. C., \&anazawa, I. (1978). The distribution of substance $P$ immunoreactive fibers in the rat central nervous system. Journal of Comparative Neurology, 178, 129-156.

Hecht, K., Oehme, P., Poppei, M., \& Hecht, T. (1979). Conditionedreflex learning of normal juvenile and adult rats exposed to action of substance $P$ and of an SP analogue. Pharmazie, 34, 419-423.

HenRY, J. L. (1980). Substance P and pain: An updating. Trends in Neuroscience, 3, 95-97.

Huston, J. P., \& StÄUbl, U. (1978). Retrograde amnesia produced by post-trial injection of substance $P$ into substantia nigra. Brain Research, 159, 468-472.

Huston, J. P., \& STÄUBL, U. (1979). Post-trial injection of substance P into lateral hypothalamus and amygdala, respectively, facilitates and impairs learning. Behavioral \& Neural Biology, 27, 244-248.

Huston, J. P., \& StÄUbLI, U. (1981). Substance P and its effects on learning and memory. In J. L. Martinez, R. A. Jensen, R. B. Messing, H. Rigter, \& J. L. McGaugh (Eds.), Endogenous peptides and learning and memory processes (pp. 521-540). New York: Academic Press.

IZQUIERDO, I. (1979). Effect of naloxone and morphine on various forms of memory in the rat: Possible role of endogenous opiate mechanisms in memory consolidation. Psychopharmacology, 66, 199-203.

Kafetzopoulos, E., HolzhäUer, M. S., \& HUSTon, J. P. (1986). Substance $P$ injected into the region of the nucleus basalis magnocellularis facilitates performance of an inhibitory avoidance task. Psychopharmacology, 90, 281-283.

KRAUTH, J. (1983). The interpretation of significance tests for independent and dependent samples. Journal of Neuroscience Methods, 9, 269-281.
LuUngDahl, A. HöKfelt, T., \& Nilsson, G. (1978). Distribution of substance P-like immunoreactivity in the central nervous system of the rat: I. Cell bodies and nerve terminals. Neuroscience, 3, 861-943.

LuNNEY, G. H. (1969). Individual size for multiple $t$-tests. American Educational Research Journal, 6, 701-703.

Sakoda, J.M., Cohen, B. H., \& BeAll, G. (1954). Test of significance for a series of statistical tests. Psychological Bulletin, 51, 172-175.

Schlesinger, K., Lipsitz, D. U., PeCK, P. L., \& Pelleymounter, M. A. (1983). Substance P reversal of electroconvulsive shock and cycloheximide-induced retrograde amnnesia. Behavioral \& Neural Biology, 39, 30-39.

Schlesinger, K., Lipsitz, D. U., Peck, P. L., Pelleymounter, M. A., Stewart, J. M., \& Chase, T. N. (1983). Substance P enhancement of passive and active avoidance conditioning in mice. Pharmacology, Biochemistry \& Behavior, 19, 655-661.

StÄUBLI, U., \& Huston, J. P. (1979). Differential effects on learning by ventromedial vs. lateral hypothalamic post-trial injection of substance P. Pharmacology, Biochemistry \& Behavior, 10, 783-786.

STÄUBLI, U., \& HuSTON, J. P. (1980). Facilitation of learning by posttrial injection of substance $P$ into the medial septal nucleus. Behavioral Brain Research, 1, 245-255.

Stern, P., \& Hadzovic, J. (1973). Pharmacological analysis of central actions of synthetic substance P. Archives International Pharmacodynamic, 202, 259-262.

Thompson, R. W., \& SPENCER, W. A. (1966). Habituation: A model phenomenon for the study of neural substrates of behavior. Psychological Review, 173, 16-43.

Tomaz, C., Aguiar, M. S., \& Nogueira, P. J. C. (in press). Memory facilitation by peripheral administration of substance $P$ and naloxone on avoidance learning and habituation. In S. Morato, A. P. Carobrez, \& T. C. M. L. Nogueira (Eds.), Neurosciences and behavior (Vol. 2) São Paulo.

Tomaz, C., \& Huston, J. P. (1986). Facilitation of conditioned inhibitory avoidance by post-trial peripheral injection of substance $P$. Pharmacology, Biochemistry \& Behavior, 25, 469-472.

Wetzel, W., Matthies, H. (1982). Effect of substance P on the retention of a brightness discrimination task in rats. Acta Biologica Medica Germanica, 41, 647-652.

(Manuscript received September 26, 1989.) 